\title{
LA VOZ Y EL EXCESO: APROXIMACIONES ESPECULATIVAS, ÉTICO-POLÍTICAS Y EDUCATIVAS A LA ORALIDAD
}

\section{Voice and excess: speculative, ethical-political and educational approaches to orality}

\author{
PEDRO BRAVO REINOSO ${ }^{*}$ \\ Hochschule für Philosophie München / Munich-Alemania \\ pedroabr@hotmail.com \\ Código Orcid: https://orcid.org/0000-0003-3619-4057
}

\begin{abstract}
Resumen
El presente artículo explora un componente poco atendido en el campo de la filosofía del lenguaje, a saber: la voz. Por medio del aparato teórico de representantes del denominado psicoanálisis esloveno, Slavoj Žižek y Mladen Dólar especialmente, se pretende mostrar que la voz es un componente de la comunicación que se resiste a su inscripción dentro de la cadena significante y por el contrario se presenta como un límite y, a la vez, un exceso en el significado, lo cual abre posibilidades para pensar la forma en la cual se da la integración de los sujetos en el orden social existente. De este modo la voz encierra en su núcleo un componente que muestra la brecha antagónica de lo social, lo cual permitiría renegociar los sentidos que ordenan lo social. El trabajo constituye una reflexión filosófica de carácter dialéctico sobre el fenómeno de la voz, ya que explora aspectos especulativos, éticos, políticos y educativos concernientes a este fenómeno, lo que pretende aportar a una comprensión de la oralidad por encima de sus aspectos instrumentales en la comunicación. Es decir, en lugar de comprender la voz como un fenómeno secundario en la comunicación orientado a servir de medio para transmitir un mensaje, la voz aparece como aquello que posibilita, interrumpe y excede las intenciones comunicativas de los sujetos que participan en el diálogo comunicativo. Finalmente, el artículo se sirve de ejemplos tomados del contexto educativo contemporáneo, en los que se muestra la manera en que la voz irrumpe en la educación como un elemento de naturaleza eminentemente política.
\end{abstract}

\footnotetext{
Palabras clave

Voz, fonocentrismo, educación, ética, política, exceso.

Forma sugerida de citar: Bravo Reinoso, Pedro (2019). La voz y el exceso: aproximaciones especulativas, éticopolíticas y educativas a la oralidad. Sophia, colección de Filosofía de la Educación, 27(2), pp. 167-184.
}

* Doctorando en Filosofía en la Hochschule für Philosophie, München. Máster en Estudios de la Cultura (Universidad Andina Simón Bolívar, Quito). Licenciado en Filosofía y Pedagogía (Universidad Politécnica Salesiana-Quito). Docente de Filosofía de la Educación en la Pontificia Universidad Católica del Ecuador. Temas de investigación desarrollados: estudios de juventud, filosofía de la educación, crítica cultural. Actualmente investiga el vínculo entre la filosofía latinoamericana de la liberación y el idealismo alemán. 


\begin{abstract}
This article explores an unattended component in the field of language philosophy, namely: the voice. Through the theoretical apparatus of representatives of the so-called Slovenian psychoanalysis, especially Slavoj Žižek and Mladen Dolar, it is intended to show that the voice is a communication component that resists its registration within the significant chain and on the contrary it is presented as a limit and, at the same time, an excess in meaning, which opens possibilities to think about the way in which the integration of the subjects occurs in the existing social order. In this way, the voice contains in its core a component that shows the antagonistic gap of the social, which would allow renegotiating the senses that order the social. The work constitutes a dialectical philosophical reflection on the phenomenon of the voice, since it explores speculative, ethical, political and educational aspects concerning this phenomenon, which aims to contribute to an understanding of orality over its instrumental aspects in the communication. That is, instead of understanding the voice as a secondary phenomenon in communication aimed at serving as a means to transmit a message, the voice appears as that which enables, interrupts and exceeds the communicative intentions of the subjects participating in the communicative dialogue. Finally, the article uses examples taken from the contemporary educational context, in which the way in which the voice bursts into education as an element of an eminently political nature is shown.
\end{abstract}

Keywords

Voice, phonocentrism, education, ethics, politics, excess.

\title{
A manera de introducción
}

Hegel en la introducción a la Fenomenología del Espíritu (2010) cuestiona la imagen del conocimiento como un mero instrumento para conocer la realidad, a la manera de unos lentes que usamos para mirar de forma más o menos clara ciertos fenómenos que se encuentra más allá del sujeto cognoscente. En esa perspectiva, la función de la teoría científica y, en nuestro caso la filosofía, es afinar dicho instrumento para que la realidad aparezca lo más nítida posible, sin manchas o señas de manipulación. Sin embargo, contrario a esta concepción del conocimiento como algo neutro, Hegel (2010) escribe categóricamente:

Pues, si el conocimiento es el instrumento para apoderarse de la esencia absoluta, salta enseguida a la vista que la aplicación de un instrumento a una Cosa no la deja tal como ella es para sí, sino que, más bien, la modela y transforma. O bien, si el conocimiento no es el instrumento de nuestra actividad, sino, en cierta medida, un medio entorno pasivo a través del cual llega hasta nosotros la luz de la verdad, tampoco ésta la obtenemos tal como ella es en sí, sino tal como ella es a través de este medio entorno, y en él (p. 143).

De esta cita se deja deducir que el conocimiento es una actividad que siempre afecta a la realidad estudiada como tal, ya sea como mediador pasivo, es decir, en cuanto una captación del objeto que únicamen- 
te acontece dentro de los límites de la conciencia, o como un mediador activo, en el sentido que la conciencia distorsiona continuamente el objeto estudiado. Un modo de evitar tales intromisiones de la conciencia en el acceso a la realidad sería eliminar del objeto los elementos que corresponden a la conciencia, pero como observa Hegel, el producto final seguiría siendo un efecto de la conciencia. Por ello, tanto la conciencia como los objetos se encuentran atrapados en un callejón sin salida: o bien conocemos la realidad solo como fragmentos dispersos que no pueden ser integrados, o la conciencia tiene que pagar el precio de renunciar a cualquier conocimiento certero y absoluto de la realidad.

La estrategia que despliega Hegel para superar esta impase, tal como comenta Žižek (2015), radica en un desplazamiento del modo cómo se comprende el problema del acceso a la realidad, ya que esto pasa de ser un problema epistemológico, entendiendo por aquello las condiciones de posibilidad que hacen válido el conocimiento de lo fenoménico, a uno fundamentalmente ontológico, puesto que las representaciones que los sujetos hacen de la realidad no son marcas externas que se adhieren a los objetos, sino que ellas son parte constitutiva de la misma. Dicho de forma resumida: la realidad se constituye también a partir de lo que el sujeto conoce de ella. La conciencia no es el problema a eliminar, sino a integrar en el objeto, de ahí que para Hegel (2010) exista una identidad especulativa entre el sujeto y el mundo, mas no en el sentido de un 'yo' abstraído de la realidad, en torno al cual la realidad tiene que acomodarse, sino que para él los objetos del mundo no son datos neutros que requieren ser procesados e interpretados por un sujeto, sino que los objetos se entienden y se comprenden como son en verdad solo y únicamente por la referencia y relación que establecen con los sujetos. La conciencia no distorsiona la realidad, sino que gracias a ella se pueden revelar nuevos aspectos de los objetos, los cuales a su vez abren la posibilidad de pensar en nuevos horizontes de comprensión de la realidad ${ }^{1}$. De ahí que en la Fenomenología del Espíritu Hegel se propone, por medio de la conciencia que alcanza el saber absoluto, superar toda fundamentación metafísica de la realidad ${ }^{2}$, esto es, para el filósofo alemán no existe una realidad noumenal que se esconde detrás del mundo de las apariencias. No hay una fundamentación absoluta de la realidad que trasciende los límites de lo que racionalmente puede ser conocido y justificado, ya que para Hegel la identidad especulativa entre sujeto y objeto no es otra cosa que el reconocimiento que los fundamentos racionales que el sujeto establece para comprender la realidad tienen un carácter absoluto, y no son meras construcciones teóricas o imágenes parcializadas de la realidad. La 
verdad radica en las apariencias, ya que, paradójicamente, el único modo de acceder al absoluto es por medio de un punto de vista situado en la realidad. Hay que insistir, lo subjetivo es la puerta que abre el camino al conocimiento de la estructura fundamental de la realidad.

Siguiendo esta línea de pensamiento, el filósofo esloveno Slavoj Žižek, plantea que un desplazamiento subjetivo en la forma de observación de un objeto conduce a una transformación ontológica en el objeto como tal. Esto es lo que él denomina la visión de paralaje:

Sujeto y objeto están inherentemente 'mediados', de modo que un desplazamiento 'epistemológico' en el punto de vista del sujeto refleja siempre un desplazamiento 'ontológico' en el objeto mismo. O para decirlo en términos lacanianos, la mirada del sujeto está inscripta desde siempre en el objeto percibido, bajo la forma de su 'punto ciego', que está 'en el objeto más que el propio objeto', el punto desde el cual el objeto devuelve la mirada (Žižek, 2016, pp. 25-26).

Esto no tiene nada que ver con cierta actitud relativista según la cual no queda más remedio que aceptar que la realidad es un conjunto de narrativas contrapuestas, todas con la misma o igual capacidad explicativa sobre el mundo. El paralaje del que habla el esloveno no es una verdad sobre la realidad que se esconde detrás de nuestras observaciones parciales, sino que la verdad es cierta brecha que constituye a la realidad como tal y que le impide a ella ser completa y plenamente tal. Leída en esta perspectiva, lo que muestra la dialéctica hegeliana es el modo cómo se emplaza la negatividad dentro de los objetos, lo que hace que estos nunca estén reconciliados consigo mismos, sino habitados por una inherente contradicción que se hace visible por medio del lugar desde el cual son observados. Las inconsistencias de nuestro conocimiento no son fallas en la observación o en el análisis de datos, sino que revelan la fuerza de la negatividad como el componente fundamental del mundo.

Mutatis mutandis esto acontece también con el lenguaje. Es decir, este no es un mero instrumento o soporte de la comunicación, como tampoco es un medio orientado únicamente a transmitir un saber 'sobre' el mundo, sino que hay una naturaleza discursiva de la realidad, ya que los distintos componentes que integran la comunicación humana revelan aspectos ontológicos de la estructura de la realidad, de tal modo que el sujeto no únicamente enuncia algo en relación con algunos aspectos del mundo, sino que por medio de sus enunciados el mundo como tal se manifiesta. Ahora bien, el lenguaje, como se pretende mostrar más adelante, no forma una red cerrada de significación, sino que se encuentra 
atravesado por una presencia excesiva, por un punto de negatividad que pone en suspenso el orden de lo simbólico y, como tal, permite visualizar los antagonismos que constituyen la realidad, y para los objetivos de este artículo, la escisión que se encuentra en la realidad social del campo educativo. Dicho elemento es la voz, la cual, desde un desplazamiento de paralaje como el que propone Žižek, se revela como la brecha en la cadena significante, como el punto que excede al ámbito de los significados. En otros términos, la voz es el elemento que en lugar de servir como vehículo de la comunicación es más bien el obstáculo que la hace posible y amenaza con diluir el sentido de las emisiones lingüísticas.

El presente artículo constituye una aproximación al fenómeno de la voz y su relevancia para comprender el campo de la educación. Para lo cual se pretende seguir las reflexiones especulativas que, en clave hegeliana-lacaniana, plantean los eslovenos Slavoj Žižek y Mladen Dolar, para así situar la voz como un fenómeno que trastoca la relación con el mundo de lo simbólico. De este modo se pretende esbozar algunos elementos teóricos relevantes para la comprensión filosófica del campo de la educación. Para desarrollar esto, se muestra como dentro de la reflexión posmoderna existe una escaza atención al problema de la voz, puesto que el francés Jacques Derrida ha instalado la idea que la deconstrucción del logos tiene que orientarse hacia el campo de lo escrito, ya que lo oral gozaría de mayor privilegio, así que en la primera sección se pretende rebatir dicha idea. A continuación se presenta la relación que la voz tiene con el denominado orden de lo simbólico, y cómo la voz, en su aspecto fenoménico, se muestra como la condición de imposibilidad de la comunicación. Finalmente, en la última sección, se presentan algunas inferencias que afectan al campo educativo y a la comprensión filosófica de la comunicación dentro de las relaciones educativas y específicamente escolares.

\section{¿La metafísica se reduce al par logocentrismo/ fonocentrismo?}

El filósofo francés Jacques Derrida (1985) en su deconstrucción de la metafísica occidental plantea que esta se ha erigido sobre el concepto de presencia como garante de la unidad y consistencia de los fenómenos. Una muestra de aquello, según Derrida, constituye la fenomenología husserliana, en la cual se aborda al fenómeno en cuanto presencia idéntica a sí misma, no condicionada, y plenamente accesible al sujeto por medio de la reducción fenomenológica. Esto es lo que se conoce como el retorno 
a las cosas mismas (Zurück zu den Sachen selbst!) que plantea Husserl (2006): "La fenomenología expresa descriptivamente, con expresión pura, en conceptos de esencia y en enunciados regulares de esencia, la esencia aprehendida directamente en la intuición esencial y las conexiones fundadas puramente en dicha esencia" (p. 216). Para Husserl, el pensar se dirige sobre objetos los cuales se presentan como unidades que pueden ser identificadas y representadas.

Ahora bien, para que la unidad del objeto se presente como tal, la percepción del mismo debe contener una unidad espacio temporal que asegure la unidad del fenómeno. Si por ejemplo observo un edificio que está frente mío, debo tener la certeza que en el pasado inmediato y en el futuro cercano dicho objeto contendrá las características de un edificio, así como también, si observo solo su cara frontal debo estar seguro que en la parte posterior seguirá siendo un edificio y no convertirse en un objeto por fuera de dicha convención. La presencia del fenómeno es cierto pacto que el sujeto realiza con los objetos para que estos puedan interactuar entre sí de forma coherente.

La deconstrucción derrideana se orienta a desestabilizar estos presupuestos, ya que enfatiza que la diferencia es parte constitutiva de los fenómenos. Derrida (1985) pretende desmontar todo el sistema de pensamiento de la metafísica occidental, para lo cual encuentra en la diferencia la condición de posibilidad de la presencia, y de la representación de la misma. No hay un acceso a la identidad en sí, porque no existe tal entidad; a lo que se tiene acceso es a la diferencia, la cual es una no-presencia:

Esta relación con la no-presencia, una vez más, no viene a sorprender, rodear, incluso disimular la presencia de la impresión originaria: permite su surgimiento y su virginidad renaciente siempre. Pero destruye radicalmente toda posibilidad de identidad consigo mismo en la simplicidad (p. 119).

Si no existiera tal diferencia las cosas siempre serían percibidas y representadas del mismo modo. Con esto, Derrida no quiere afirmar que habitamos en un mundo ficticio en el cual las cosas, como el edificio del ejemplo anterior, espontáneamente se transforman en seres mitológicos o implosionan en la nada. Para Derrida hay un aspecto en los fenómenos que no puede ser simbolizado plenamente y cuyo significado varía de contexto a contexto. No obstante, esta apertura a la diferencia se consigue para Derrida únicamente por medio de la escritura, ya que los textos ofrecerían una plasticidad expresiva e interpretativa que el lenguaje cotidiano, 
específicamente el habla no la tiene. De ahí que la deconstrucción se halla desarrollado fundamentalmente por medio de los estudios literarios.

En esta perspectiva, lo literario se muestra a sí mismo como un recurso de emancipación, mientras que lo sonoro, la voz, aparece más bien como un elemento, por decirlo de alguna manera, retardatario ya que la misma se resiste a captar la diferencia como tal, y se refugia en cierta unidad sustancial de los fenómenos. Es por ello que para Derrida la metafísica de la presencia no es sino otra denominación del fonocentrismo, puesto que el logos siempre se ha mostrado inmanente a la palabra hablada. La escritura, en esta perspectiva, ha estado supeditada a lo fonético porque la voz se pronuncia sobre la presencia de un objeto, mientras que la escritura no remite directamente a un objeto, sino que éste se presenta como ausente, por tal razón, para el pensamiento occidental, la escritura ha conducido a equívocos:

En la medida en que la idealidad del objeto parece depender de la voz, y llegar a estar así absolutamente disponible en ella, el sistema que liga la fenomenalidad a la posibilidad del Zeigen [apuntar, señalar] funciona mejor que nunca en la voz. El fonema se da como la idealidad dominada del fenómeno (Derrida, 1985, p. 136).

Según esto, voz y logos se presentan como elementos vinculados en una línea de continuidad, como aquellos que aseguran la consistencia de la realidad en su aspecto ontológico ${ }^{3}$. Sin embargo, ¿Es la voz un mero mediador evanescente que se somete a los objetos? ¿La literatura es la única vía de escape a cualquier tipo de metafísica? Para el filósofo esloveno Mladen Dolar la articulación logos/voz no es tan sencilla como la muestra el deconstructivismo, puesto que dentro de la historia de la metafísica las discontinuidades entre la ellos son mucho más evidentes de lo que Derrida consideró ${ }^{4}$, lo que implicaría una revisión del rol que ocupa la voz en su relación con los fenómenos. El objetivo de Dolar es mostrar que la voz no es el mero acompañante del logos, aquel vehículo de lo racional, sino que hay en la voz elementos que transgreden al logos como tal y que deben ser visibilizados.

\section{El carácter excesivo de la voz}

Dolar propone un análisis político del fenómeno de la voz, para lo cual señala cómo a partir de Aristóteles la voz no es una mera articulación sonora por medio de la cual se comunican los significantes, sino que en ella radica el origen de la política. A este respecto, el estagirita señala lo siguiente: 
La razón por la cual el hombre es un ser social, más que cualquier abeja y que cualquier animal gregario, es evidente: la naturaleza, como decimos, no hace nada en vano, y el hombre es el único animal que tiene palabra. Pues la voz es signo de dolor y del placer, y por eso la poseen también los animales, porque su naturaleza llega hasta tener sensación de dolor y de placer e indicársela unos a otros. Pero la palabra es para manifestar lo conveniente y lo perjudicial, así como lo justo y lo injusto (Aristóteles, 1988, pp. 50-51).

La distinción fundamental entre hombres y animales radica en la posesión del habla (logos), la cual a diferencia de la mera voz (phoné), no se limita al ámbito de lo sensible, a la mera percepción de las cosas y en un comportamiento cuasi instintivo, sino que es capaz de generar una relación mediada con el mundo y por tanto juzgar éticamente los actos para así identificar aquello que hace más bien a la comunidad, lo que se acerca a los ideales de justicia y rectitud política. En este caso, el habla viene a señalar el punto de ruptura de lo animal con lo humano, su falta de continuidad, pero como observa Dolar (2007), esto no reposa en un mero naturalismo, es decir, en un fenómeno biológico, sino que la constitución de la palabra tiene una naturaleza política, en tanto que la cuestión definitiva de la polis consiste en la pregunta de a quién otorgar y asimismo a quién negar la capacidad de palabra ${ }^{5}$. Así en el ámbito de lo público hay unos sujetos que emiten discursos racionales, y otros, que pese a utilizar el lenguaje, bordean el umbral de la animalidad y su discurso es reducido a exclamaciones movidas por impulsos que no poseen ninguna validez ni legitimidad. El logos de forma retroactiva establece a aquellos sujetos que únicamente emiten sonidos (mera voz), de aquellos que únicamente pueden comunicar 'sonidos' en el espacio público.

La voz no es ningún tipo de remanente de un estado biológico precultural, sino que es producto del logos, ella es aquello que vigoriza y a la vez perturba al habla. Por ello, para Dolar (2007) el concepto de fonocentrismo no hace justicia al hecho que la voz, en lugar de ser un epifenómeno de lo racional, ha sido más bien caracterizada como elemento asociado con lo residual, lo sensual, la animalidad y por ello con lo contingente, contrario con la palabra escrita, particularmente la ley, que reposa por encima de su condición de estar o no pronunciada:

La historia del 'logocentrismo' no va necesariamente de la mano con el 'fonocentrismo', que hay una dimensión de la voz que corre a contramano de la transparencia de sí, del sentido y de la presencia: la voz contra el logos, la voz como lo otro del logos, su radical alteridad. La 'metafísica' siempre tuvo conciencia de eso [...] aferrándose compulsivamente a 
una misma fórmula de exorcismo, repitiéndola una y otra vez, compelida con la misma mano invisible a lo largo de milenios. Puede que lo que la defina como metafísica [sea] la prohibición de la voz (Dolar, 2007, p. 67).

¿Cuál es la necesidad de prohibir o a lo sumo controlar la voz? ¿Cuál es el aspecto monstruoso que esta encierra? Slavoj Žižek (2007) comenta que en la voz no hay una relación de transparencia entre el sujeto y la cosa pronunciada, ni mucho menos del sujeto consigo mismo. Cuando el sujeto se escucha a sí mismo hablar se produce un cortocircuito en su identidad, ya que este se fractura y en la escucha de su voz hay el reconocimiento de un cuerpo extraño que lo habita ${ }^{6}$. La 'voz de la conciencia' figura paradigmática en cuentos infantiles viene a ejemplar muy bien esta situación, porque indica la irrupción de un agente extraño al personaje y que le impide escucharse a sí mismo. O también se puede pensar en la reacción de un sujeto cuando se escucha hablar por medio de una grabación radiofónica: ‘ ¿así me escucho yo? ¿soy yo el que realmente está hablando?’ Žižek dice a este respecto:

La 'identidad propia' de la voz reside en el hecho de que la voz como medio de autopresencia transparente coincide con la voz como cuerpo ajeno que socava mi autopresencia 'desde dentro'. En la tensión antagónica entre el significante y el objeto, la voz está entonces del lado del objeto: la voz en su dimensión fundamental, no es el significante ideal (totalmente transparente, maleable y modesto), sino todo lo contrario, la inercia opaca del resto de un objeto (p. 100).

La voz no se define por su aspecto utilitario, no está orientada a satisfacer una necesidad, en este caso generar las condiciones para la comunicación entre sujetos, sino posee una naturaleza disruptiva, está plagada de un exceso que hace que el diálogo pierda su carácter de ser un mero vínculo cara a cara, ya que la voz, en su irrupción efímera en el encuentro intersubjetivo, es aquella parte del significante que se resiste a la significación, pues los significados de un enunciado pueden convertirse en su contrario por un modo determinado de presencia de la voz. Esto es semejante a cuando un educador pregunta sus estudiantes si han entendido la lección, y todos en coro responden al unísono y de forma cuasi estridente 'iSí!'. La voz, en este caso, cumple una función contraria a la comunicación, ya que es el excedente que pone en riesgo la generación de sentido en el habla, por ello, el diálogo educativo en este caso, para que pueda funcionar, necesita de cierto autoengaño en los sujetos que participan en el mismo, y hay que pagar un precio: anular el componente 
excesivo de la voz para así tomar el significado en su forma literal, aunque ni educadores ni estudiantes crean realmente lo que han escuchado y emitido respectivamente.

Visto así la voz se encuentra en una posición ambigua. Por un lado su existencia depende del sujeto, necesita que alguien la pronuncie, pero por otro lado, su consistencia y credibilidad la adquiere por su referencia a otro ${ }^{7}$, al orden de lo simbólico, a la causa en la cual el sujeto está comprometido. Esto es semejante a lo que Heidegger (1993) plantea con el 'llamado de la conciencia', en el cual, el único modo que tiene el Dasein de salir del anonimato de una existencia en la cual ya está interpretado y sumido en la masa, es escuchar aquella voz que lo impulse a asumir su condición de proyecto y proyectado en el mundo. Esta voz no tiene un origen trascendente, sino que emerge del propio Dasein aunque no le pertenezca del todo:

La circunstancia de que la vocación no sea hecha expresamente por mí, antes bien voque 'algo', no autoriza todavía a buscar al vocador en un ente cuya forma de ser no sea la del 'ser ahí Éste existe en cada caso fácticamente. No es un proyectarse flotante en el vacío, sino que definido por el 'estado de yecto' como factum del ente que él es, ha sido en cada caso ya y sigue siendo constantemente entregado a la responsabilidad de la existencia (Heidegger, 1993, p. 300).

Esto permite colegir otro de los aspectos fundamentales de la voz. En su referencia al Otro, la voz no hace más que mostrar la inconsistencia o incompletud que caracteriza a este. En esto radica el aspecto ético de la voz, ya que es el punto de coincidencia de dos faltas: tanto la falta en el sujeto (el sujeto no es quien emite la voz), como también la falta en el Otro (la causa a la que el sujeto busca comprometerse tampoco está plenamente realizada, es un proyecto, no existe por sí misma). Lo ético de la voz consiste en mostrar que el orden social al cual esta apela, a la posibilidad de un consenso intersubjetivo que permite coordinar intenciones y acciones, en realidad está plagado por un antagonismo inherente que lo impide ser. Más cuando la voz pretende suturar el vacío del Otro se deviene en usos autoritarios y represivos de la voz. Dolar (2007) ofrece dos casos extremos para comprender esto.

El primer caso al que hace referencia es a la voz de Hitler, el líder carismático que encandiló a las audiencias por su capacidad retórica. La voz del Führer debe su efectividad, como muestra Dolar, por ocupar la voz del Otro, es decir, lo que ella menciona produce performativamente el orden jurídico de lo social y el modo de inserción del sujeto dentro de 
ese orden. Su voz, por sí misma, articula el significado de la nación y de lo político. Se trata de una voz que pasa por encima de las leyes, que las reescribe, ya que su enunciación tiene el efecto de generar órdenes que deben cumplirse de inmediato.

El otro ejemplo que cita Dolar es el caso de la burocracia soviética en el período estalinista. En este caso la voz de los funcionarios es una voz carente de vivacidad, es una voz opaca que se limita a repetir de forma mecánica la letra de los documentos. Este uso atonal de la voz cumple la función de servir a un orden burocrático, el cual se muestra a sí mismo como el representante del pueblo. Por tanto, genera la fantasía de un ordenamiento social que funciona y se sostiene gracias a las infaltables trabas de las mediaciones burocráticas.

Dolar, como se ha dicho, llega a la conclusión que la voz emerge en el entrecruce de dos faltas: la del sujeto y del Otro, de ahí que la eticidad que esta anuncia implica asumir el carácter indeterminado de lo social, puesto que la voz es el exceso que a la vez transgrede y sostiene el funcionamiento de lo simbólico.

\section{La voz en lo educativo: el caso de la educación bancaria y sus interpelaciones}

El filósofo de la educación Paulo Freire (2005) enfatizó el rol que juega el lenguaje como componente decisivo de la práctica educativa liberadora. Él advirtió de la educación bancaria, esto es, una educación carente de diálogo en la cual los contenidos de aprendizaje son meros requisitos burocráticos que deben ser depositados en los estudiantes, se fundamenta en la capacidad de transmitir un mensaje de forma transparente y sin vestigios de elementos residuales en el acto de enseñanza. Esta educación, decimos, muestra que la voz del maestro y la voz de los estudiantes cumple la función de servir a los rituales institucionales que pretenden asegurar el presunto carácter pleno de la escuela, la nación, la cultura, etc. Esta educación, desde la perspectiva que venimos trabajando, forman parte de ritos que ayudan a satisfacer al Otro, en los cuales el sujeto se entrega, dona una parte de sí, para que el Otro adquiera su imposible consistencia. Piénsese por ejemplo en los actos donde fundamentalmente prima la voz: la iza de una bandera, el canto de un himno, los discursos cívicos o religiosos, entre otros, son una performance de la voz en la cual el objetivo es mostrar que el orden social en el cual los sujetos están inscritos funciona realmente, que efectivamente hay una identidad colectiva a la cual 
los sujetos pueden adscribirse y que les brinda seguridad. Pero su misma enunciación, como tratamos de mostrar, hace que reemerjan por medio de la voz elementos que exceden a estas representaciones fundadas en la reconciliación social. Tomemos unos ejemplos.

En junio de 2018 en la ciudad de Quito un grupo de estudiantes secundarios de una importante institución educativa pública difundieron por redes sociales un video en el que se puede observar la siguiente escena: un profesor, con un palo en la mano, ordena que un grupo de estudiantes formen una fila frente a él, puesto que presumiblemente han cometido alguna falta disciplinaria considerada grave. En el video se observa que, como muestra de castigo, el profesor procede a infringir un golpe - no tan fuerte- en el trasero de cada uno de estos jóvenes.

La escena, que si bien parece sacada de The Wall-Pink Floyd, se difundió y, como es de esperarse en este tipo de casos, provocó reacciones distintas entre quienes apoyan tales medidas como ejemplares para corregir el comportamiento de los jóvenes, y aquellos que la rechazan por su falta de pertinencia. En cualquier caso, lo más llamativo fue la reacción de los padres de familia de dicha institución, puesto que una vez que se conoció que dicho profesor fue sancionado y separado de la institución por parte de las autoridades educativas, los padres organizaron una marcha no solo para pedir el reingreso del profesor, sino también para que ese tipo de prácticas retornen de manera más firme a las escuelas. ¿Nostalgia de la voz del Otro que irrumpa en lo social por fuera de toda mediación? Esto es una muestra de cómo funciona la fantasía ideológica de la educación bancaria: no interesa juzgar los mecanismos instituciones que tiene una escuela para resolver los problemas de convivencia, tampoco interesa juzgar la efectividad de la violencia física — cualquiera sabe que un golpe con un palo no va a cambiar la vida de un joven, mucho menos cuando aquello se escenifica ante una cámara—, sino dicha ideología crea la imagen que los niños o jóvenes son los que causan tales desórdenes en la escuela y por ende, el castigo muestra que ellos constituyen la excepción necesaria que fortalece la institucionalidad y las prácticas pedagógicas tradicionales.

Del mismo modo, los educadores necesitan saber que lo que hacen sigue funcionando, que las metodologías que aplican son todavía relevantes y que el contenido que enseñan tiene todavía algún sentido, aunque en el fondo reconozcan que no es así. Como diría Žižek (2003, p. 57) "ellos saben muy bien lo que hacen, pero aún así, lo hacen", puesto que existe la confianza que la escuela es todavía el lugar del gran Otro, el espacio que puede conferir sentido y orientación a sus vidas y la de los educandos, o al menos tienen que escenificar o ritualizar la escuela como 
si esta todavía puede funcionar con la estructura que la vio surgir y por medio del refuerzo de los métodos pedagógicos de tipo bancario.

Sin embargo, como sugieren los pedagogos argentinos Ignacio Lewkowics y Cristina Corea (2005) nos encontramos en la época en la que prima la pedagogía del aburrido puesto que se tienen educadores que 'simulan' enseñar y educandos que 'simulan' aprender; educadores que 'simulan' disciplinar y educandos que 'simulan' obedecer; educadores que 'simulan' poseer el monopolio de la palabra y educandos que 'simulan' escuchar, etc. La escuela del simulacro es aquella que no es capaz de enfrentar las transformaciones culturales y aquella que externaliza sus problemas en unos sujetos particulares: los estudiantes 'disfuncionales' o problemáticos. Pero lo que Freire viene a poner en tensión es que la escuela solo podrá cumplir tal cometido si se convierte en un sitio de disputa constante, si se atreve a dar el paso de reconstruirse y desestructurarse. En otras palabras, un espacio que permita la irrupción ética de la voz.

Lo ético, hay que enfatizar, radica paradójicamente en un elemento no ético, a saber: en la posibilidad de mostrar que lo social está atravesado por una falla constitutiva que pone en riesgo todo tipo de convenciones sociales. Esto es lo que la filósofa eslovena Alenka Zupančič (2011) denomina una ética de lo real. Es decir, una ética en la cual el sujeto no solo se define por su compromiso por una causa, sino que además, dicho compromiso puede conducir al sacrificio de la causa como tal. Sacrificio en el sentido de despojar los ideales éticos como un campo de valores que permanece más allá de las contingencias del mundo material y finito, como si los ideales fueran siempre la salvaguarda o recurso que va a socorrer al sujeto en momentos de profunda ansiedad. Lo que muestra Zupančič, repitiendo un movimiento hegeliano, es que los valores no son algo que están 'más allá', sino que la contingente, abrupta e inconsistente realidad social está atravesada por un exceso, que ella es posible gracias a un aspecto infinito, absoluto. Razón por la cual hay que encontrar la brecha, el punto en el cual lo social se quiebra y no puede reconciliarse consigo mismo. La voz, en este caso, expresa un momento de duplicidad de la realidad, de un desdoblamiento en la realidad finita que muestra el abismo infinito que la constituye.

Por ello la voz se eleva hacia lo ético y lo político cuando deja de ser un mero instrumento para satisfacer rituales sociales, y cuando evita su enunciación autoritaria, es decir, cuando el sujeto se escenifica como la encarnación del orden social. En este espacio intermedio, en la brecha entre el sujeto y el orden social es cuando actúa la voz como un elemento ético-político. Ético porque impulsa a reconsiderar las convenciones so- 
ciales y muestran a un sujeto que excede a las mismas, y político porque se orienta a generar otras condiciones, asimismo contingentes y provisorias para vivir en sociedad. Dolar (2007) dice sobre esto:

Tenemos que desenmarañar, de entre las voces sonoras y estridentes, la voz no sonora de la pura enunciación, la enunciación sin enunciado: la enunciación a la que hay que proveerle el enunciado, el enunciado político en respuesta a esa voz: no escuchando/obedeciendo, no efectuando meros rituales sociales, sino comprometiéndose en una postura política (2007, p. 146).

Un ejemplo paradigmático constituye el movimiento ecológico desplegado por la joven activista sueca Greta Thunberg Fridays for future, que ha despertado la atención de miles de estudiantes secundarios 180 en varias partes del mundo ya que, contrario a lo que se pueda pensar, no es una mera huelga escolar que busca reemplazar la educación por una forma de activismo político, sino que pone en evidencia los mismos objetivos de lo educativo, a saber: la capacidad que tienen las instituciones educativas de formar a las nuevas generaciones en su plena inserción y participación en la sociedad. Esta huelga juvenil pone en la mesa de debate las preguntas educativas por excelencia ¿para qué sociedad nos educamos? ¿cuál futuro anuncia la educación? La forma de la huelga va en consonancia con lo que hemos querido señalar con respecto de la voz, ya que la manifestación callejera es la expresión por antonomasia de la voz, de esta voz ético-política que quiere negociar los significados y los sentidos de lo social, porque es una voz que muestra la contingencia y precariedad con la que se construyen los mismos.

Así, por medio de carteles, consignas y demás elementos 'auditivos' o que rebasan la mera literalidad de los discursos, esta voz pone en evidencia el abismo constitutivo del actual orden democrático. Es un momento político por excelencia, que ha provocado reacciones que buscan apaciguar esta voz y volverla a circunscribir en los límites de la educación bancaria. Muestra de esto último constituyen las reacciones del político alemán Christian Lindner quien, a inicios de marzo de 2019, ante las réplicas que hubo en el país teutón de las huelgas escolares ante el cambio climático, catalogó que el cuidado del clima no es un asunto para niños y jóvenes, sino para 'profesionales', y por ende, la función de los estudiantes dentro de la escuela debe seguir siendo la misma: formarse académicamente para que en un futuro su voz se inserte en las instituciones ya existentes. A los pocos días de dicha declaración aconteció algo realmente sorprendente. Científicos de Alemania, Austria y Suiza se sumaron a las 
huelgas por una mejor política climática y declararon rotundamente: Wir sind die Profis und sagen: Die junge Generation hat Recht (Nosotros somos los expertos y decimos: la juventud tiene razón $)^{8}$.

Una política educativa de la voz no se limita a la letra de los textos o al mero uso de herramientas digitales como recursos educativos, sino que genera condiciones de diálogo en el que la voz cumple una doble función: mostrar la brecha que atraviesa al Otro y mostrar a su vez el carácter excesivo y disruptivo que tiene la subjetividad. El caso de Fridays for future es paradigmático, porque no se trata únicamente de un reclamo dirigido a la clase política, sino que es un movimiento que se dirige contra sí mismo, es decir, son jóvenes que protestan contra su mismo estilo de vida, ya que reconocen que aquello que hacen en su cotidiano tiene graves consecuencias en la sostenibilidad del planeta. Por ello la voz permanece como un elemento extraño al sujeto y extraño a lo social, y es en esa apertura donde opera lo educativo como práctica liberadora.

\section{Conclusiones}

Hay una relación dialéctica entre la voz y la palabra. Es decir, por más que lo racional intente instaurarse como una instancia en la que prima lo argumental, requiere de un excedente que la haga posible, caso contrario, el logos queda como 'letra muerta' incapaz de generar algún tipo de efecto sobre lo social. Lo educativo es un espacio en el que la voz manifiesta este rol, puesto que, pese a que el contenido de enseñanza reposa en los textos escolares o es accesible por medio de diversas plataformas digitales, su pronunciación en clase hace que adquiera efectividad y gane legitimidad. Incluso hay contenidos que solo se transmiten por medio de la voz, porque permanecen como el reverso oscuro de las planificaciones institucionales. Se puede pensar por ejemplo en el 'curriculum oculto' el cual no es la enseñanza explícita, sino unos hábitos y modos de comprensión de la realidad que se forman por el carácter excesivo de la voz.

La voz, por tanto, escapa de ser un mero recurso retórico para transmitir un mensaje, o para liderar una clase ante un grupo de estudiantes. La voz es el límite del diálogo intersubjetivo, es aquello que imposibilita y a la vez permite la comunicación, porque se plantea lo que franquea a lo simbólico, pero a su vez permite su redefinición. La voz, en cuanto excedente, es aquello que permite deslindarse de las narrativas consensuales del lenguaje, en el cual la comunicación, una vez que ha eliminado puntos antagónicos, puede articular ideas y acciones entre sujetos. Como 
hemos visto, en la voz hay un resto que resiste a la significación, de ahí que el debate político, y educativo, gire también entorno a las voces que pueden ser escuchadas, las que disputan los significados, y las voces no audibles porque su sola presencia resultan un exceso insoportable.

Visto así, la educación bancaria es el lugar 'utópico' al que aspira la institución educativa, ya que se funda en la reciprocidad en el intercambio de significantes: los enunciados son comprendidos y reproducidos tal como estos son emitidos. Frente a esa fantasía, la tarea de una educación liberadora, no es meramente generar otro escenario utópico, sino arriesgarse a mostrar que en la voz de los educadores y los educandos si bien hay un cierto acto ventrílocuo, pero también entraña la posibilidad de habitar temporalmente en el antagonismo que estructura al sujeto y su sociedad.

\section{Notas}

1 Rolf-Peter Hortsmann (2008, p.74) resume la identidad especulativa sujeto-objeto en cuatro aspectos fundamentales: 1) hay un sujeto se relaciona de modos distintos con los objetos del mundo; 2) cada una de estos modos de relacionamiento pueden ser identificados y diferenciados; 3 ) dentro de cada relación con el mundo hay una pretensión de verdad; 4) la verdad alcanza su punto máximo de expresión cuando el objeto se identifica con el concepto que el sujeto ha desarrollado. Esto último sólo se consigue si el sujeto ha atravesado distintos estadios de desarrollo o experiencias de conciencia.

2 Rebasa los límites de este trabajo el hacer un análisis más detallado de lo que Hegel entiende por este saber absoluto como el punto culminante del devenir sujeto de la sustancia. Mas lo que es importante considerar es que no se trata de una ontología determinista que reduce al sujeto y al objeto a simples medios de manifestación de un Absoluto que está más allá de la conciencia, ni mucho menos Hegel se propone establecer el acceso al 'ojo de Dios' como el punto de vista que reúne todos los puntos de vista, o lo que es lo mismo, una mirada desconectada y abstraída de toda realidad concreta. Para una revisión más detallada del carácter posmetafísico de la Fenomenología del Espíritu se puede revisar Pinkard (1994, pp. 221-268), Solomon (1983, pp. 187-210; 295-318; 635-640), Taylor (2010, pp. 66-110; 183-192).

3 Se puede pensar por ejemplo en la función que cumple la voz en off como recurso cinematográfico. Este elemento narrativo no solo sirve de orientación para el espectador para saber de primera mano los sentimientos y la autopercepción del protagonista de la historia, sino que marca también un punto en el cual personaje se divide en dos: por un lado está el personaje que persigue un deseo dentro de la historia y que se enfrenta a su antagonista para alcanzarlo, y por otro está su voz, la cual emerge como un elemento que ya se ha redimido del conflicto que atraviesa la historia, porque es una voz que ya sabe lo que va a pasar en la historia, y por ello, a nosotros, los espectadores, de algún modo nos tranquiliza saber que el personaje saldrá victorioso.

4 Muestra de ello es el estatuto metafísico que ha tenido la voz en la reflexión filosófica en la antigüedad y edad media, específicamente en lo concerniente a la música, ya que sobre ella, autores tan diversos como Platón o Agustín coinciden en la imposibilidad que tiene la voz como elemento para mostrar la esencia de las cosas, y en su 
lugar proponen cierta proscripción de la voz en cuanto ella constituye una corrupción del logos, puesto que se trata de un elemento asociado con la sensualidad y lo accidental (Dolar, 2007, pp. 57-67).

5 Este planteamiento se encuentra en íntima relación con lo que plantea el filósofo francés Jacques Rancière (1996), quien señala que el ordenamiento democrático se funda por medio de la exclusión, de una parte-sin-parte en lo social, que sirve no como meros sujetos que están por fuera de lo político, sino que, en su exclusión, hacen posible la institucionalidad de la democracia.

6 La voz, para Žižek, es la encarnación de cierto goce, es decir, del reverso obsceno que constituye a lo social, como aquella transgresión inherente que funda a lo social. Así para Žižek la política no es lo contrario al dominio de los impulsos que amenazan a lo social, sino que ella se funda en un modo de regular dicho gozo. Para una explicación más detallada de la relación entre política y gozo dentro del pensamiento žižekiano, así como también la función que cumple el lenguaje en este interrelación, se puede revisar Finkelde (2013, pp. 19-76).

7 El concepto de Otro con mayúsculas, el gran Otro, hace referencia a lo que en el campo lacaniano se conoce como la red sociocultural de reglas y costumbres lingüísticamente mediadas que organizan lo social, o la inserción del sujeto en lo social. De ahí que el Otro sea quien estructure el deseo, por cuanto se presenta como la instancia que puede restituir la pérdida que advino al sujeto por su inserción en el orden de lo simbólico. El Otro entraña una promesa de completud aunque permanezca inaccesible: "Si la palabra se funda en la existencia del Otro, el verdadero, el lenguaje está hecho para remitirnos al otro objetivado, al otro con el que podemos hacer todo cuanto queremos, incluido pensar que es un objeto, es decir, que no sabe lo que dice. Cuando nos servimos del lenguaje, nuestra relación con el otro juega todo el tiempo en esa ambigüedad. Dicho en otros términos, el lenguaje sirve tanto para fundarnos en el Otro como para impedirnos radicalmente comprenderlo. Y de esto precisamente se trata en la experiencia analítica” (Lacan, 1991, p. 244) (Lacan, 1991, p. 244).

8 Traducción personal. A este respecto se puede revisar el siguiente artículo periodístico (Brech, 2019).

\section{Bibliografía}

Aristóteles

1988 Política (M. García Valdés, trad.). Madrid: Gredos.

Brech, S. M.

29 de marzo de 2019. Wir sind Profis und sagen: Die junge Generation hat recht. Recuperado de https://bit.ly/2uznRfA (20-mayo-2019).

DERRIDA, Jacques

1985 La voz y el fenómeno. Introducción al problema del signo en la fenomenología de Husserl. Valencia: Pre-Textos.

DOLAR, Mladen

2007 Una coz y nada más. Buenos Aires: Manantial.

FINKELDE, Dominik

2013 Slavoj Žižek zwischen Lacan und Hegel. Politische Philosophie, Metapsychologie, Ethik. Wien/Berlín: Turia + Kant. 
FREIRE, Paulo

2005 Pedagogía del oprimido. México: Siglo XXI.

HEGEL, Georg Wilhelm Friedrich

2010 Fenomenología del espíritu (A. Gómez Ramos, trad.). Madrid: Abada.

HEIDEGGER, Martin

1993 Ser y tiempo (2a ed.). Fondo de Cultura Económica.

HORTSMANN, Rolf-Peter

2008 Hegels Phänomenologie des Geistes als Argument für eine monistische Ontologie. En Klaus Vieweg y Wolganf Welsch (Ed.), Hegels Phänomenologie des Geistes. Ein kooperativer Kommentar zu einem Schlüsselwerk der Moderne (pp. 58-78). Frankfurt am Main: Suhrkamp.

HUSSERL, Edmund

2006 Investigaciones lógicas I. Madrid: Alianza.

LACAN, Jacques

1991 The ego in Freud's theory and in the technique of psychoanalysis, 19541955. En Norton Paperback: Vol. 2. New York: W.W. Norton.

LEWKOWICS, Ignacio \& COREA, Cristina

2005 Pedagogía del aburrido: escuelas destituidas, familias perplejas. Buenos Aires: Paidós.

PINKARD, Terry

1994 Hegel's Phenomenology. The Sociality of Reason. Cambridge: Cambridge University Press.

RANCIÈRE, Jacques

1996 El desacuerdo. Política y filosofía. Buenos Aires: Ediciones Nueva Visión.

SOLOMON, Robert

1983 In the Spirit of Hegel. A Study of G.W.F. Hegel's Phenomenology of Spirit. New York/Oxford: Oxford University Press.

TAYLOR, Charles

2010 Hegel. Barcelona/México: Anthropos Editorial/Universidad Iberoamericana/Universidad Autónoma Metropolitana.

ŽIŽEK, Slavoj

2007 The indivisible remainder:on Schelling and related matters. En Radical thinkers. London, New York: Verso.

2015 Menos que nada. Hegel y la sombra del materialismo dialéctico. Madrid: Akal.

2016 Visión de paralaje. Ciudad de México: Fondo de Cultura Económica.

ZUPANČIČ, Alenka

2011 Ética de lo real: Kant, Lacan. Buenos Aires: Prometeo Libros.

Fecha de recepción de documento: 10 de diciembre de 2018

Fecha de revisión de documento: 20 de febrero de 2019

Fecha de aprobación de documento: 25 de abril de 2019

Fecha de publicación de documento: 15 de julio de 2019 